\title{
IMPLEMENTASI HOSPITAL BYLAWS \\ DI RUMAH SAKIT SANTO ANTONIO BATURAJA \\ SETELAH BERLAKUNYA PERMENKES NOMOR: 755/MenKes/Per/IV/2011 TENTANG PENYELENGGARAAN KOMITE MEDIK DI RUMAH SAKIT
}

\author{
Lucia Murniati, Endang Wahyati Y. dan Siswo Putranto Santoso \\ luciamurniati@yahoo.com \\ Magister Hukum Kesehatan \\ Universitas Katolik Soegijapranata Semarang
}

\begin{abstract}
ABSTRAK
Hospital Bylaws mengatur tentang hak dan kewajiban pemilik, direktur, staf medis, tenaga kerja lainnya dan pasien yang memiliki sifat "tailor made", namun tetap diperlukan sebagai sarana pengaturan atau hukum dasar bagi rumah sakit, yang isi dari Hospital Bylaws merupakan kekhususan dari setiap rumah sakit.

Penelitian ini menggunakan pendekatan yuridis empiris, studi penelitian ini membahas aspek yuridis dan sekaligus membahas aspek sosial yang melingkupi gejala hukum tertentu. Metode analisis yang digunakan analisis kualitatif yaitu melakukan analisis data yang telah dikumpulkan dari hasil observasi di lapangan dan hasil wawancara dengan responden, dilengkapi data sekunder dari Rumah Sakit St. Antonio Baturaja serta data sekunder berupa kepustakaan hukum.

Ketentuan hukum mengenai Hospital Bylaws didasarkan pada UU Praktek Kedokteran, UU Pelayanan Publik, UU Kesehatan dan UU Rumah Sakit. Hospital Bylaws merupakan kewajiban bagi Rumah Sakit maka Rumah Sakit Santo Antonio Baturaja menyusun dan melaksanakan Hospital Bylaws. Pelanggaran atas kewajiban dapat dikenakan sanksi administrasi. Bentuk pengaturan Hospital Bylaws adalah PerMenKes Nomor: 755/MenKes/Per/IV/2011 Tentang Penyelenggaraan Komite Medik Di Rumah Sakit dengan tujuan mengatur tata kelola klinis yang baik agar mutu pelayanan medis dan keselamatan pasien lebih terjamin dan terlindungi serta mengatur penyelenggaraan komite medik di setiap rumah sakit dalam rangka meningkatkan profesionalisme staf medis. Implementasi di Rumah Sakit Antonio Baturaja belum berjalan sesuai dengan ketentuan karena dipengaruhi oleh faktor yuridis dan faktor teknis Persoalan yuridis adalah PerMenKes Nomor: 755/MenKes/Per/IV/2011 seharusnya tidak mengatur Hospital Bylaws karena merupakan instrumen yang berbeda.
\end{abstract}

Kata Kunci : Rumah Sakit, Hospital Bylaws, Komite Medik 


\section{PENDAHULUAN}

Rumah sakit merupakan suatu organisasi yang sangat berbeda dan sangat unik dibandingkan dengan institusi-institusi lainnya. Organisasi rumah sakit sangat rumit, dikarenakan mengatur semua kebijakan dan kegiatan yang terdiri dari satuan kerja yang berbeda dalam tugas, peran dan tanggungjawabnya, namun harus bekerjasama dalam melaksanakan kegiatan pelayanan kesehatan yang komprehensif. Rumah Sakit dan dokter berperan sebagai pemberi jasa pelayanan kesehatan, sedangkan pasien sebagai penerima jasa pelayanan kesehatan. Pelaksanaan hubungan antara dokter, rumah sakit dan pasien selalu diatur dengan peraturanperaturan tertentu supaya terjadi keharmonisan dalam melaksanakan hubungan. Peraturanperaturan ini dituangkan dalam aturan main yang dibentuk di rumah sakit khusus untuk kepentingan rumah sakit yang bersangkutan.'

Dilihat dari hubungan hukum antara dokter dan pasien, hubungan dokter dengan rumah sakit dan hubungan pasien dengan rumah sakit merupakan hubungan saling sepakat untuk mengikatkan diri yang dikenal dengan perikatan (Verbentenis). Perikatan yang digunakan sebagai hubungan hukum di atas adalah merupakan perikatan ikhtiar (inspanning verbentenis) yaitu merupakan upaya seoptimal mungkin untuk mencapai pelayanan kesehatan bagi pasien yang diobati, bukan merupakan perikatan hasil (resultaat verbentenis). Tujuan paling hakiki dari keberadaan peraturan perundang-undangan adalah untuk menciptakan Kepastian hukum. ${ }^{2}$ Kepastian hukum ini meliputi segala upaya berdasarkan hukum untuk melindungi rumah sakit sebagai penyelenggara kesehatan dan perlindungan terhadap pasien. ${ }^{3}$

Rumah sakit diakui merupakan institusi yang sangat kompleks dan berisiko tinggi (high risk), terlebih dalam kondisi lingkungan regional dan global yang sangat dinamis perubahannya. Salah satu pilar pelayanan medis adalah clinical governance, dengan unsur staf medis yang dominan. Direktur rumah sakit bertanggung jawab atas segala sesuatu yang terjadi di rumah sakit sebagaimana dimaksud dalam Pasal 46 Undang-Undang Nomor 44 Tahun 2009 tentang Rumah Sakit. Keberadaan staf medis dalam rumah sakit merupakan suatu keniscayaan karena kualitas pelayanan rumah sakit sangat ditentukan oleh kinerja para staf medis di rumah sakit tersebut. Yang lebih penting lagi kinerja staf medis akan sangat mempengaruhi keselamatan pasien di rumah sakit. Untuk itu rumah sakit perlu menyelenggarakan tata kelola klinis (clinical governance) yang baik untuk melindungi pasien. Hal ini sejalan dengan amanat peraturan perundangundangan yang terkait dengan kesehatan dan perumahsakitan.

Belakangan ini tidak jarang keluhan masyarakat bahwa rumah sakit tidak melayani masyarakat dengan baik. Menurut Wila Chandrawila Supriadi, pasien adalah orang sakit yang membutuhkan pertolongan dokter untuk menyembuhkan penyakit yang dideritanya. ${ }^{4}$ Bahkan beberapa rumah sakit saat ini telah dituntut karena pelayanan yang tidak sesuai harapan. Seringkali pasien berpendapat bahwa kerugian yang diderita oleh pasien adalah disebabkan oleh kesalahan ataupun kelalaian yang diperbuat dokternya, padahal untuk membuktikan kerugian itu disebabkan oleh kesalahan atau kelalaian dokter adalah pekerjaan yang tidak mudah, karena kedudukan antara dokter dan pasiennya ini adalah bersifat subordinat, dokter sebagai tenaga yang ahli dibidangnya, sedangkan pasien adalah orang yang membutuhkan pertolongan dari dokter.

\footnotetext{
1 Sofwan Dahlan, 2005, Hukum Kesehatan, Rambu-rambu bagi Profesi Dokter, ed. 3, Badan Penerbit Universitas Dipenogoro, Semarang

2 C.S.T Kansil dan Christine S.T Kansil, 2010, Pengantar Ilmu Hukum Indonesia, Cahaya Atma Pustaka, Yogyakarta, hlm. 43

3 Titik Triwulan Tutik, 2010,Perlindungan Hukum Bagi Pasien, Prestasi Pustaka, Jakarta, hlm. 39

4 Wila Chandrawila Supriadi, 2001, Hukum Kedokteran, Mandar Maju, Bandung, hlm. 20
} 
Dalam rangka melindungi penyelenggaraan rumah sakit, tenaga kesehatan dan melindungi pasien maka rumah sakit perlu mempunyai peraturan internal rumah sakit yang biasa disebut Hospital Bylaws. Peraturan tersebut meliputi aturan-aturan berkaitan dengan pelayanan kesehatan, ketenagaan, administrasi dan manajemen. Tujuan hukum bukan hanya kepastian hukum, tetapi juga keadilan dan kemanfaatan hukum. ${ }^{5}$

Bentuk dari Hospital Bylaws dapat merupakan Peraturan Rumah Sakit, Standard Operating Procedure (SOP), Surat Keputusan, Surat Penugasan, Pengumuman, Pemberitahuan dan Perjanjian (MOU). Peraturan internal rumah sakit (HBL) antara rumah sakit satu dengan yang lainnya tidak sama materi muatannya, hal tersebut tergantung pada sejarahnya, pendiriannya, kepemilikannya, situasi dan kondisi yang ada pada rumah sakit tersebut. Namun demikian peraturan internal rumah sakit tidak boleh bertentangan dengan peraturan diatasnya.

Permasalahan yang dihadapi oleh para pemilik dan pengelola Rumah Sakit kian beragam, sementara jaminan atas perlindungan dan keselamatan Pasien tetap merupakan hal utama dalam pengelolaan suatu Rumah Sakit. Untuk menjamin mutu pelayanan kesehatan serta melindungi keselamatan pasien, maka profesionalisme staf medis menjadi mutlak/perlu ditingkatkan, dengan profesionalisme tersebut, diharapkan pasien akan memperoleh pelayanan yang terbaik dan dapat dipertanggungjawabkan. Komite Medik di tiap Rumah Sakit memegang peranan penting dan strategis untuk mengendalikan kompetensi serta perilaku staf medis guna menunjang profesionalisme tersebut.

Dalam rangka mencapai tujuan tersebut maka Tata Kerja serta Tata Kelola Komite Medik Rumah Sakit saat ini telah dilakukan upaya perbaikan dan penyempurnaan. Paradigma lama yang menempatkan Komite Medik "seolah" sejajar dengan Manajemen Rumah Sakit sehingga mengambil banyak peran dalam pengelolaan Rumah Sakit, kini telah ditata ulang kembali.

Permenkes No. 755/Menkes/Per/IV/2011 telah mengarahkan serta membentuk paradigma baru yang menempatkan Komite Medik sebagai organisasi non struktural di Rumah Sakit yang mempunyai peran strategis/penting "hanya" di bidang pengelolaan profesi medis yang lebih profesional. Untuk mencapai keselarasan atas kepentingan pihak pemilik Rumah Sakit, pihak pengelolaan Rumah Sakit serta pihak Staf Medis selaku pelaksana pemberi layanan medis kepada pasien maka mutlak harus dibuat aturan bersama dalam bentuk Hospital Bylaws/HBL, Corporate Bylaws/CBL, serta Medical/Clinical Staff Bylaws/CSBL. Aturan inilah yang mengatur hak, kewajiban, tugas serta kewenangan para pihak yang terkait di Rumah Sakit tersebut.

Pada Pasal 29 ayat (1) huruf r Undang-undang Nomor 44 Tahun 2009 Tentang Rumah Sakit menyebutkan bahwa rumah sakit harus menyusun dan melaksanakan peraturan internal rumah sakit (hospital bylaws). Dalam meningkatkan kesadaran hukum, peraturan internal rumah sakit tersebut menjadi acuan yang sangat penting bagi rumah sakit. Ini berarti rumah sakit mempunyai dua fungsi sebagai institusi yang merupakan subyek hukum yang dapat melakukan perbuatan hukum dalam masyarakat dan sebagai lembaga pelayanan publik yang bertanggungjawab terhadap tenaga professional yang dalam melakukan kegiatannya didasarkan pada etik. ${ }^{6}$

Fungsi pelayanan kesehatan oleh rumah sakit akan menjadi optimal jika setiap tenaga kesehatan menurut jenis profesinya bekerja sesuai dengan standar pelayanan rumah sakit, standar operasional prosedur dan standar profesinya sebagai mana yang diamanahkan dalam Undang-Undang Nomor 25 tahun 2009 tentang Pelayanan Publik. Tanggung jawab publik rumah sakit sebagai penyelenggara pelayanan publik diatur dalam ketentuan Pasal 15 Undang-Undang

5 Sudikno Martokusumo, 1999, Mengenal Hukum: Suatu Pengantar, Yogyakarta Liberty, hlm. 24

6 Mutu Pelayanan Kesehatan http://www.mutupelayanankesehatan.net/index.php/publikasi/artikel/9- publikasi/184harapan-direktur-terhadap-perilaku-dokter-spesialis-dan-dokter, diuduh tanggal 10 Juli 2013 
Nomor 25 Tahun 2009, tentang Pelayanan Publik yaitu mengatur tentang tujuan pelaksanaan pelayanan publik, antara lain :

a) terwujudnya batasan dan hubungan yang jelas tentang hak, tanggung jawab, kewajiban dan kewenangan seluruh pihak yang terkait dengan penyelenggaraan pelayanan publik.

b) terwujudnya sistem penyelenggaraan pelayanan yang layak sesuai dengan asas-asas umum pemerintahan dan korporasi yang baik

c) terpenuhinya penyelenggaraan pelayanan publik sesuai dengan peraturan perundangundangan

d) terwujudnya perlindungan dan kepastian hukum bagi masyarakat dalam penyelenggaraan pelayanan publik.

Pelayanan kesehatan di rumah sakit makin berkembang terus dengan bertambahnya berbagai macam spesialisasi kedokteran. Tenaga kesehatan harus dipacu dengan peningkatan mutu dan kualitas. ${ }^{7}$ Hal ini bila tidak diatur dengan benar akan menyebabkan persinggungan antara pemilik, pihak manajemen, staf medis, tenaga kesehatan lain dan pasien yang dapat menurunkan citra rumah sakit.

Oleh sebab itu rumah sakit berkewajiban mengatur pertanggungjawaban hukum dan medis dalam suatu peraturan internal rumah sakit yang didalamnya mengatur mengenai hak dan kewajiban, tanggungjawab serta wewenang, sehingga ada kejelasan dan ketegasan bagi masingmasing pihak. Oleh karenanya setiap pihak yang terkait, dapat dipertanggungjawabkan atas kesalahan dan kelalaian yang telah dilakukannya. Rumah Sakit banyak atau sedikit akan dipengaruhi oleh kemampuan profesional dari "Medical Staff” yang memegang posisi penting. ${ }^{8}$

Hospital Bylaws ini tidak hanya mengikat secara internal yakni tidak hanya mengikat bagi tenaga medis saja. Sedangkan bagi pasien yang merasa dirugikan dalam pelayanan medis tetap saja tidak tahu kepada siapa harus meminta pertanggungjawaban hukum. Pada kenyataannya, upaya penyelesaian sengketa yang telah dilakukan saat ini tidak dapat memuaskan pihak pasien sebagai pihak yang dirugikan, sedangkan bagi dokter dan rumah sakit timbulnya sengketa merupakan hal yang ditakuti karena berkaitan dengan martabat dan nama baik. Sehingga sangat dibutuhkan kepastian hukumnya. ${ }^{9}$ Hospital Bylaws ini merupakan perwujudan dari asas kepastian hukum. Asas kepastian hukum ini memberikan jaminan kepada para pihak yang terlibat di dalam pelayanan medik di rumah sakit untuk bertanggungjawab secara hukum dalam hal terjadinya suatu sengketa. Demikianpun Hospital Bylaws seharusnya menjadi dasar hukum dari kegiatan penyelenggaraan pelayanan medik di rumah sakit. ${ }^{10}$

Rumah Sakit St. Antonio Baturaja adalah rumah sakit swasta milik Yayasan Santo Georgius yang didirikan berdasarkan Akte Notaris Dwi Hartiningsih SH, Nomor 01 tanggal 15 Oktober 2009, yang berkedudukan di Sleman - Yogyakarta, berdasarkan Surat ljin Penyelenggaraan Rumah Sakit Nomor : DINKES No.445/01/XIV/2.2/SK.RS/2012 tanggal 04 April 2012. Yayasan Santo Georgius adalah adalah Yayasan yang mempunyai maksud dan tujuan dibidang sosial, kemanusiaan dan keagamaan yang bersifat "nirlaba", artinya kegiatan Yayasan bukan untuk mencari keuntungan, tetapi sebagai badan hukum yang terdiri atas kekayaan yang dipisahkan untuk maksud dan tujuan tertentu dibidang sosial, keagamaan dan kemanusiaan. ${ }^{11}$ Untuk maksud dan tujuan tersebut maka didirikanlah Rumah Sakit St. Antonio Baturaja. Untuk mencapai visi dan misi, Rumah sakit harus diselenggarakan secara baik dan bertanggungjawab karena rumah sakit merupakan Subyek Hukum, yang memiliki kewenangan untuk melakukan

7 H. Bambang Poernomo, Tanpa Tahun, Hukum Kesehatan, Aditya Medi, Yogyakarta, hlm. 361

8 Hermien Hadiati Koeswadji, 2002, Hukum Untuk Perumahsakitan, Citra Aditya Bhakti, Bandung, hlm. 96

9 Alexandra Ide, 2012, Etika dan Hukum Dalam Pelayanan Kesehatan, Grasia Publisher, hlm. 291

10 J. Guwandi, 2004, Merangkai Hospital Bylaw, Jakarta, hlm. 8

11 H.P. Panggabean, 2002, Paradigma Baru Dalam Pengelolaan Yayasan, Jakarta, hlm.162 
perbuatan hukum. ${ }^{12}$ Rumah Sakit St. Antonio berkewajiban pula untuk melaksanakan dan menerapkan Peraturan Internal Rumah Sakit (Hospital Bylaws) dalam setiap penyelenggaraan pelayanan kesehatan di rumah sakitnya sesuai dengan peraturan perundang-undangan yang berlaku.

Berdasarkan latar belakang masalah di atas maka peneliti tertarik untuk meneliti mengenai "Implementasi Hospital Bylaws di Rumah Sakit Baturaja Setelah Berlakunya Permenkes Nomor: 755/Menkes/Per/IV/2011 Tentang Penyelenggaraan Komite Medik Di Rumah Sakit

\section{RUMUSAN MASALAH}

Berdasarkan latar belakang dan permasalahan yang timbul sebagaimana telah disampaikan diatas, maka diperoleh pokok permasalahan yang akan diteliti yaitu:

1. Bagaimana konsep pengaturan tentang Hospital Bylaws di Rumah Sakit?

2. Bagaimana pengaturan tentang Penyelenggaraan Komite Medik dalam Hospital Bylaws di Rumah Sakit Santo Antonio Baturaja?

3. Faktor-Faktor apakah yang mempengaruhi implementasi Hospital Bylaws berdasarkan PERMENKES Nomor: 755/MenKes/Per/IV/2011 tentang Penyelenggaraan Komite Medik Di Rumah Sakit, Pada Rumah Sakit Santo Antonio Baturaja.

\section{PEMBAHASAN}

\section{Ketentuan Hukum Tentang Hospital Bylaws di Rumah Sakit Santo Antonio Baturaja}

a. Dasar hukum dari Hospital Bylaws diatur dalam:

1) Pasal 1, Pasal 14, dan Pasal 30 Undang-Undang Republik Indonesia Nomor 36 tahun 2009 tentang Kesehatan.

Adanya Hospital Bylaws, dapat dikategorikan dalam upaya kesehatan yang dilaksanakan oleh rumah sakit sebagai upaya paripurna. Dimana menurut UU Kesehatan disebutkan:

Pasal 1

(11) Upaya kesehatan adalah setiap kegiatan dan/atau serangkaian kegiatan yang dilakukan secara terpadu, terintegrasi dan berkesinambungan untuk memelihara dan meningkatkan derajat kesehatan masyarakat dalam bentuk pencegahan penyakit, peningkatan kesehatan, pengobatan penyakit, dan pemulihan kesehatan oleh pemerintah dan/atau masyarakat.

Upaya kesehatan yang dilakukan oleh rumah sakit dalam hal ini bersifat paripurna, dimana tujuan akhirnya rumah sakit dapat terjamin dalam menjalankan tugasnya yang berujung pada terciptanya perlindungan hukum bagi semua pihak dalam pelayanan kesehatan.

Terkait dengan pasal ini Rumah Sakit Santo Antonio Baturaja, harus menyelenggarakan upaya kesehatan baik promotif, preventif, kuratif maupun rehabilitative.

12 Endang Wahyati Yustina, 2012, Mengenal Hukum Rumah Sakit, Bandung, hlm. 69 
Pasal 14 UU Kesehatan Pemerintah mempunyai tanggung jawab:

1. Pemerintah bertanggungjawab merencanakan, mengatur, menyelenggarakan, membina dan mengawasi, penyelenggaraan upaya kesehatan yang merata dan terjangkau oleh masyarakat.

2. Tanggungjawab Pemerintah sebagamana dimaksud pada ayat (1) dikhususkan pada pelayanan publik.

Berdasarkan ketentuan di atas, peran pemerintah dalam mengatur, menyelenggarakan, membina dan mengawasi Rumah Sakit maka membuat suatu kebijakan publik guna mencegah terjadinya konflik baik internal maupun eksternal di rumah sakit yang disebut dengan Hospital Bylaws.

Disamping tanggung jawab pemerintah yang telah diuraikan di atas, mengingat rumah sakit merupakan salah satu pusat rujukan pelayanan kesehatan maka dalam Pasal 30 UU Kesehatan.

Berdasarkan ketentuan pasal di atas, rumah sakit wajib memenuhi standar fasilitas pelayanan kesehatan dan ketentuan perizinan fasilitas kesehatan. Hospital Bylaws sebagai sarana untuk menjamin efektifitas, efesiensi serta mutu bagi pelayanan kesehatan di rumah sakit maka Hospital Bylaws menjadi pedoman bagi semua yang berhubungan dengan rumah sakit.

Hal ini sejalan dengan tujuan Hospital Bylaws di Rumah Sakit Santo Antonio Baturaja. Terkait dengan perizinan yang mensyaratkan adanya kewajiban memenuhi standar fasilitas kesehatan, maka Rumah Sakit Santo Antonio Baturaja membuat pedoman yang berlaku bagi semua, baik untuk tingkat rumah sakit maupun untuk masing-masing pelayanan misalnya pelayanan medis, pelayananan keperawatan, administrasi dan manajemen, rekam medis, pelayanan gawat darurat, dan sebagainya.

Beberapa pasal dalam UU Kesehatan di atas menjadi payung hukum bagi rumah sakit dalam menyusun dan melaksanakan Hospital Bylaws.

2) Pasal 29 Undang-Undang Republik Indonesia Nomor 44 Tahun 2009 Tentang Rumah Sakit

Rumah sakit juga memiliki kewajiban dalam melayani pasiennya. Kewajiban rumah sakit itu sudah tentu mengikat juga pada para tenaga medis. Pasal 29 menyatakan kewajiban rumah sakit, diantaranya pada huruf $r$ : Menyusun dan melaksanakan peraturan internal Rumah Sakit (hospital by laws). Terkait dengan pasal ini, maka rumah sakit wajib menyusun dan melaksanakan peraturan internal Rumah Sakit (hospital by laws).

Hospital Bylaws merupakan suatu kewajiban yang harus dipenuhi, maka dengan demikian Rumah Sakit Santo Antonio Baturaja menyusun dan melaksanakan Hospital Bylaws. Pelanggaran atas kewajiban dikenakan sanksi administratif dimana menurut UU Rumah Sakit disebutkan:

Pasal 29 ayat (2): Teguran; Teguran tertulis; atau Denda dan pencabutan izin rumah sakit

\section{b. Bentuk Pengaturan Hospital Bylaws}

Bentuk ketentuan pelaksanaan yang terkait dengan Hospital Bylaws yaitu: Peraturan Menteri Kesehatan No: 755/MENKES/PER/IV/2011 Tentang Penyelenggaraan Komite Medik Di Rumah Sakit. 
Peraturan Menteri Kesehatan ini bertujuan untuk mengatur tata kelola klinis yang baik agar mutu pelayanan medis dan keselamatan pasien di rumah sakit lebih terjamin dan terlindungi serta mengatur penyelenggaraan komite medik di setiap rumah sakit dalam rangka peningkatan profesionalisme staf medis. Hal ini seperti terlihat dalam Pasal 4, dimana Komite Medik dibentuk dengan tujuan untuk menyelenggarakan tata kelola klinis yang baik agar mutu pelayanan medis dan keselamatan pasien lebih terjamin dan terlindungi.

Pada Ketentuan Penutup PerMenKes No. 755 disebutkan bahwa pada saat Peraturan Menteri Kesehatan ini mulai berlaku maka Keputusan Menteri Kesehatan Nomor 772/MENKES/SK/VI/2002 tentang Pedoman Peraturan Internal Rumah Sakit (Hospital Bylaws) dicabut dan dinyatakan tidak berlaku lagi, artinya bahwa pada saat ini bentuk Hospital Bylaws harus sesuai dengan PerMenKes No. 755. Hospital Bylaws merupakan instrumen yuridis sedangkan Komite Medik adalah instrumen lembaga maka pengaturan ini tidak tepat jika dianalisis didasarkan pada pendapat W. Riawan Tjandra. Dalam perspektif Hukum Administrasi Negara, Hospital Bylaws merupakan instrumen yuridis. Pelaksanaan fungsi pemerintahan dilakukan dengan mendayagunakan instrumeninstrumen pemerintahan. Instrumen-instrumen pemerintahan dapat diklasifikasikan menjadi:

1. Instrumen yuridis, meliputi: peraturan perundang-undangan, peraturan kebijaksanaan, rencana, dan instrumen hukum keperdataan;

2. Instrumen materiil;

3. Instrumen personil/kepegawaian

4. Instrumen keuangan negara. ${ }^{13}$

Pelaksanaan fungsi pemerintahan dilakukan dengan mendayagunakan instrumeninstrumen pemerintahan (pelayanan publik) termasuk Rumah Sakit sebagai bentuk pelayanan publik. Instrumen-instrumen tersebut meliputi: Instrumen yuridis, Instrumen lembaga, Instrumen personil/kepegawaian dan Instrumen keuangan

Komite Medik termasuk dalam instrumen lembaga dan instrumen kepegawaian yang diatur dalam Hospital Bylaws. Hospital Bylaws Rumah Sakit Santo Antonio Baturaja. Hospital Bylaws mengatur segala aktifitas rumah sakit termasuk Komite Medik merupakan salah satu obyek yang diatur dalam Hospital Bylaws.

\section{c. Tujuan Pengaturan Hospital Bylaws}

Hospital Bylaws disusun dan dilengkapi dengan aturan yang dibuat oleh institusi untuk mengatur semua unsur yang terlibat dalam penyelenggaraan rumah sakit seperti: medik, paramedik, non paramedik dan lain-lain, juga untuk memfasilitasi sengketa hukum baik internal maupun eksternal.

Hospital Bylaws menjadi instrumen dalam pelaksanaan akreditasi rumah sakit. Rumah sakit perlu membuat standar-standar yang berlaku baik untuk tingkat rumah sakit maupun untuk masing-masing pelayanan misalnya pelayanan medis, pelayananan keperawatan, administrasi dan manajemen, rekam medis, pelayanan gawat darurat, dan sebagainya.

13 W. Riawan Tjandra, 2008, Hukum Administrasi Negara, Universitas Atma Jaya Yogyakarta, HIm. 24 


\section{Implementasi Hospital Bylaws Rumah Sakit Santo Antonio Baturaja}

Sesuai dengan Peraturan Menteri Kesehatan No: 755/MENKES/PER/IV/2011 Tentang Penyelenggaraan Komite Medik Di Rumah Sakit Bab I Ketentuan Umum Pasal 1 ayat 1 disebutkan bahwa:

Komite Medik adalah perangkat rumah sakit untuk menerapkan tata kelola klinis agar staf medis di rumah sakit terjaga profesionalismenya melalui mekanisme kredensial, penjagaan mutu profesi medis dan pemeliharaan etika dan disiplin profesi medis.

Sedangkan pada ayat 4 disebutkan bahwa:

Peraturan Internal Rumah Sakit (Hospital Bylaws) adalah aturan dasar yang mengatur tata cara penyelenggaraan rumah sakit meliputi peraturan internal korporasi (corparate governance) dan peraturan internal staf medis (medical staff bylaws).

Unsur yang telah diimplementasikan di Rumah Sakit Santo Antonio Baturaja terdiri dari:

1. Instrumen yuridis

Hospital Bylaws Rumah Sakit Santo Antonio Baturaja adalah aturan yang dibuat oleh institusi untuk mengatur semua unsur yang terlibat dalam penyelenggaraan rumah sakit.

2. Instrumen lembaga

Setiap peraturan yang terdapat di Rumah Sakit Santo Antonio Baturaja dibuat oleh pejabat yang berwenang. Adanya struktur dalam penyelenggaraan rumah sakit yang mempunyai tugas dan wewenang sesuai dengan bidangnya.

3. Instrumen personil/kepegawaian.

Rumah Sakit Santo Antonio Baturaja mempunyai peraturan tentang kepegawaian yang mengatur mengenai hak dan kewajiban semua yang terlibat dalam penyelenggaraan rumah sakit termasuk komite medik.

4. Instrumen keuangan

Instrumen keuangan merupakan instrumen yang penting untuk menyelenggarakan rumah sakit. Penyelenggaraan fungsi-fungsi rumah sakit tidak akan bisa dilaksanakan secara efektif tanpa didukung oleh sarana keuangan. Sedemikian pentingnya maka Rumah Sakit Santo menggatur mengenai penggajian dan biaya operasional rumah sakit.

Rumah Sakit Santo Antonio Baturaja belum membuat Hospital Bylaws yang baru dan merevisi Hospital Bylaws karena Peraturan Menteri Kesehatan No: 755/MENKES/PER/IV/2011 Tentang Penyelenggaraan Komite Medik mengubah berbagai hal penting dalam menyelenggarakan organisasi rumah sakit sedangkan pemahaman mengenai pentingnya Hospital Bylaws masih terbatas dan ketersediaan sumber daya yang sangat kurang.

\section{Faktor-Faktor Yang Mempengaruhi Implementasi Hospital Bylaws Di Rumah Sakit St. Antonio Baturaja}

Adapun faktor-faktor yang mempengaruhi implementasi peraturan internal rumah sakit di rumah sakit St. Antonio Baturaja adalah sebagai berikut:

\section{a. Faktor Yuridis}

1) Pada Pasal 1 Peraturan Menteri Kesehatan No: 755/MENKES/PER/IV/2011 Tentang Penyelenggaraan Komite Medik Di Rumah Sakit disebutkan bahwa:

Komite Medik adalah perangkat rumah sakit untuk menerapkan tata kelola klinis agar staf medis di rumah sakit terjaga profesionalismenya melalui mekanisme kredensial, 
penjagaan mutu profesi medis dan pemeliharaan etika dan disiplin prefesi medis. Dalam Komite Medik tidak memiliki perlindungan hukum bagi tenaga kesehatan yang lain sedangkan dalam Hospital Bylaws melindungi banyak pihak di rumah sakit.

Dalam akreditasi rumah sakit khususnya kelompok kerja Administrasi dan Manajemen bila tidak ada Hospital Bylaws maka akan mendapat skor o (nol) atau dapat membuat pengajuan akreditasi rumah sakit tidak lulus. Jadi Hospital Bylaws dibuat sekedar memenuhi persyaratan perijinan rumah sakit.

2) Rumah Sakit yang berbadan hukum Yayasan akan sulit menyesuaikan dengan PerMenKes Nomor 755/MENKES/PER/IV/2011 terutama dalam hal kelembagaan karena yang berwenang untuk melakukan penandatanganan dokumen terkait dengan penyelenggaraan rumah sakit adalah pihak Yayasan. Hal ini berpotensi menimbulkan persoalan hukum khususnya berkaitan dengan kewenangan.

3) Jangka waktu penyesuaian seperti tertulis dalam PerMenKes Nomor 755/MENKES/PER/IV/2011 sangat tidak cukup terutama bagi rumah sakit yang jauh dari pusat pemerintahan dengan kondisi keuangan dan jumlah pasien yang terbatas.

\section{b. Faktor Teknis}

Faktor teknis yang mempengaruhi implementasi peraturan internal rumah sakit di rumah sakit St. Antonio Baturaja sebagai berikut, yaitu:

1) Faktor sumber daya manusia yang terbatas

Sumber Daya Manusia : kualitas dan kuantitas. Pengurus Yayasan belum mengetahui tentang pentingnya peraturan internal rumah sakit di rumah sakit sedangkan Direktur dan Staf Medik merasa hanya sebagai pelaksana. Instrumen kebijakan sebagian besar berupa surat edaran dan kewenangan hanya bersumber pada keputusan Pengurus Yayasan sehingga mengakibatkan peraturan internal rumah sakit yang baik belum berjalan secara optimal.

2) Faktor komunikasi yang belum baik

Terputusnya komunikasi antara Pengurus Yayasan, Direktur dan Staf Medis. Rapatrapat maupun sosialisasi Hospital Bylaws tidak ada, pedoman sudah ada dan mengakui pentingnya Hospital Bylaws namun belum pernah membaca sehingga implementasi belum terlaksana. Hospital Bylaws hanya sebagai prasyarat akreditasi rumah sakit.

3) Faktor pengawasan yang belum optimal

Lemahnya penegakkan Hospital Bylaws dikarenakan tidak adanya pengawasan sesuai dengan instrumen kebijakan rumah sakit baik dari internal maupun eksternal.

4) Faktor struktur birokrasi yang belum berjalan dengan

semestinya. Semua standar operasional yang ada di rumah sakit mengacu pada Hospital Bylaws karena sama-sama bersifat teknis dan koordinasi antar lembaga belum terbentuk. 


\section{PENUTUP}

\section{KESIMPULAN}

Dari uraian di atas ini, beberapa hal yang dapat ditarik sebagai kesimpulan dari pembahasan implementasi Hospital Bylaws di rumah sakit St. Antonio Baturaja, adalah sebagai berikut:

1. Pengaturan hukum tentang kewajiban menyusun dan melaksanakan peraturan internal rumah sakit (Hospital Bylaws) dasar hukumnya yaitu :

a. Undang-Undang Republik Indonesia Nomor 29 tahun 2004 tentang Praktik Kedokteran

b. Undang-Undang Republik Indonesia Nomor 25 tahun 2009 tentang Pelayanan Publik

c. Undang-Undang Republik Indonesia Nomor 36 tahun 2009 tentang Kesehatan

d. Undang-Undang Republik Indonesia Nomor 44 Tahun 2009 Tentang Rumah Sakit

Bentuk pengaturan Hospital Bylaws adalah Peraturan Menteri Kesehatan No: 755/MENKES/PER/IV/2011 Tentang Penyelenggaraan Komite Medik Di Rumah Sakit. Hospital Bylaws merupakan suatu kewajiban yang harus dipenuhi, pelanggaran atas kewajiban dikenakan sanksi administratif.

2. Implementasi Hospital Bylaws di Rumah Sakit Santo Antonio Baturaja sesuai dengan Peraturan Menteri Kesehatan No: 755/MENKES/PER/IV/2011 Tentang Penyelenggaraan Komite Medik Di Rumah Sakit tidak dapat seluruhnya dilaksanakan karena beberapa kendala. Hospital Bylaws di Rumah Sakit Santo Antonio Baturaja untuk saat ini dibuat hanya untuk memenuhi standar akreditasi rumah sakit.

3. Faktor-faktor yang mempengaruhi implementasi peraturan internal rumah sakit di rumah sakit St. Antonio Baturaja terdiri dari :

a) Faktor yuridis yakni Komite Medik tidak menjamin perlindungan hukum bagi tenaga kesehatan yang lain, Hospital Bylaws dibuat sekedar memenuhi persyaratan perijinan rumah sakit, status badan hukum suatu rumah sakit mempengaruhi kewenangan dalam penyelenggaraan rumah sakit serta jangka waktu penyesuaian yang pendek.

b) Faktor teknis berupa sumber daya manusia yang masih terbatas, komunikasi yang belum baik, pengawasan yang belum optimal dan struktur birokrasi yang belum berjalan dengan semestinya.

\section{SARAN}

Saran yang dapat diberikan dari pembahasan penelitian ini, yaitu:

1. Bagi Kementerian Kesehatan

Meninjau kembali KEPMENKES NOMOR 755/MENKES/PER/IV/2011 dilihat dari Hukum Administrasi Negara terutama tentang instrumen hukum. Meningkatkan pengawasan terhadap pelaksanaan peraturan tersebut.

2. Bagi Rumah Sakit

Perlunya mensosialisasikan Peraturan Internal Rumah Sakit (Hospital Bylaws) pada Yayasan dan setiap lapisan organisasi di rumah sakit serta membuat perencanaan yang mengakomodir Hospital Bylaws. Menyusun dan melaksanakan Hospital Bylaws tidak hanya untuk memenuhi kewajiban tetapi untuk perlindungan hukum bagi semua pihak di rumah sakit 
3. Bagi Pengurus Yayasan

Menjalankan fungsi Pengurus Yayasan sesuai dengan regulasi yang telah ditetapkan dan meningkatkan komitmen untuk membuat Hospital Bylaws sesuai dengan peraturan yang berlaku.

\section{DAFTAR PUSTAKA}

Alexandra Ide, 2012, Etika dan Hukum Dalam Pelayanan Kesehatan, Grasia Publisher

C.S.T Kansil dan Christine S.T Kansil, 2010, Pengantar Ilmu Hukum Indonesia, Cahaya Atma Pustaka, Yogyakarta

Endang Wahyati Yustina, 2012, Mengenal Hukum Rumah Sakit, Bandung

H. Bambang Poernomo, Tanpa Tahun, Hukum Kesehatan, Aditya Medi, Yogyakarta

Hermien Hadiati Koeswadji, 2002, Hukum Untuk Perumahsakitan, Citra Aditya Bhakti, Bandung

H.P. Panggabean, 2002, Paradigma Baru Dalam Pengelolaan Yayasan, Jakarta

J. Guwandi, 2004, Merangkai Hospital Bylaw, Jakarta

Wila Chandrawila Supriadi, 2001, Hukum Kedokteran, Mandar Maju, Bandung

W. Riawan Tjandra, 2008, Hukum Administrasi Negara, Universitas Atma Jaya Yogyakarta

Sofwan Dahlan, 2005, Hukum Kesehatan, Rambu-rambu bagi Profesi Dokter, ed. 3, Badan Penerbit Universitas Dipenogoro, Semarang

Sudikno Martokusumo, 1999, Mengenal Hukum: Suatu Pengantar, Yogyakarta Liberty

Titik Triwulan Tutik, 2010,Perlindungan Hukum Bagi Pasien, Prestasi Pustaka, Jakarta

\section{PERUNDANG-UNDANGAN:}

Undang-Undang Republik Indonesia Nomor 28 tahun 2004 tentang Yayasan

Undang-Undang Republik Indonesia Nomor 29 tahun 2004 tentang Praktik Kedokteran

Undang-Undang Republik Indonesia Nomor 25 tahun 2009 tentang Pelayanan Publik

Undang-Undang Republik Indonesia Nomor 36 tahun 2009 tentang Kesehatan

Undang-Undang Republik Indonesia Nomor 44 Tahun 2009 Tentang Rumah Sakit

Keputusan Menteri Kesehatan No: 755/MENKES/PER/IV/2011 Tentang Penyelenggaraan Komite Medik Di Rumah Sakit

\section{INTERNET}

Mutu Pelayanan Kesehatan

http://www.mutupelayanankesehatan.net/index.php/publikasi/artikel/9-publikasi/184harapan-direktur-terhadap-perilaku-dokter-spesialis-dan-dokter, diuduh tanggal 10 Juli 2013 